\title{
The comparative sensory analysis of mint honey
}

\author{
Constanta Laura AUGUSTIN (ZUGRAVU) ${ }^{1}$, Maria Magdalena TUREK \\ RAHOVEANU*2, and Gheorghe Adrian ZUGRAVU ${ }^{3 *}$ \\ 1 "Dunărea de Jos” University of Galaţi, Romania, zugravulaura@yahoo.com; \\ 2 "Dunărea de Jos" University of Galaţi, Romania, mturek2003@yahoo.com; \\ 3 "Dunărea de Jos" University of Galaţi, Romania, zugravuadrian@yahoo.com
}

\begin{abstract}
The aim of the paper is to present sensory analysis of mint honey as a component of the promotion strategy of intensive beekeeping. Sensory analysis is part of the quality concept and is the method of examining a product with the help of basic human sensation.
\end{abstract}

Keyword: mint honey, sensory analysis.

\section{Introduction}

The sensory analysis provides the encompassing variety in five modes of contact without, however, representing awareness of the action of the varied external or internal stimulus [1], [2], [3]. The first sort of informational communication with the external world is that the sensory reception [4], [5]. The primary psychic product of sensory reception is sensation [6], [7]. The feeling is that the psychic reflection of some isolated properties of the objects of reality that act directly on the sense organs [8], [9]. Therefore the reflection of the thing within the sensation features a fragmentary character, one-dimensional, not allowing its identification [10], [11]. If we remain within the phase of sensory reception, without the attribute of awareness, we couldn't detach ourselves from the animal world [12]

In humans, the notice of the feeling puts into operation logical operators of analysis-evaluation, discernment-delimitation between the stimulus and its informational model, of designative reporting (the internal subjective image refers to the external stimulus that caused it the sensations are characterized by a series of qualities on the idea of which we will identify, compare, analyze, and interpret. These qualities are: modality, intensity, duration, affective tone and cognitive value. Counting on the character of the sources that generate them, the sensations are: the sources are external, the sources are at the extent of the muscular joints and the sources are internal, at the extent of the viscera. At the bottom of the feeling may be a special functional property of the animal organisms, the sensitivity. Sensitivity is that the function of cells called receptors that appear and gradually differentiate during the evolution and is exerted as a function of a selected apparatus called sensory integration system or analyzer. At the bottom of the dynamics of sensitivity are three categories of laws:

- Psychophysical laws - expresses the relation between the sensitivity level and therefore the physical intensity of the stimulus;

- Psycho physiological laws - it expresses the dependence of the feeling not only on the physical properties of the stimulus but also on the physiological variations within each analyzer or on the interaction between the analyzers.

\footnotetext{
*Corresponding author: mturek2003@yahoo.com
} 


\section{Materials and Methods}

Quality is the totality of the characteristics of a product, capable of satisfying the needs of consumers. Sensory analysis methods can be objective and subjective.

Sensory analysis is part of the set of modern analytical methods: applied correctly, scientifically, it allows realizing a real evaluation of the quality of the food products, an evaluation that could not be obtained only by the appreciation of the physic-chemical and microbiological methods, because the latter does not highlight the sensory value. Sensory analysis, as the scientific method of assessing the properties of foods, has an important role in establishing the authenticity of the products, it is used for comparison with the reference products, in classification and standardization, as well as in detecting the prospects, defects and other shortcomings. Although sensory analysis is dependent on human appreciation, it has a certain degree of subjectivism, due to the professionalization of the body of tasters and statistical interpretation, is a useful tool, and in some cases becomes irreplaceable in the assessment of quality.

\section{Principle of the method}

The honey is homogenized and left to rest and it is well homogenized and appreciated such as: transparent, bright, opalescent or cloudy. Fuzzy comparative sensory analysis is a scientific method that can be used to interpret recorded data of sensations [13]. This method use analysis criterion of the quality of honey in the case of work. Analysis is a particularly important method for assessing the quality of food, which can be objective and subjective in determining properties, having an important role in establishing authenticity, in classification and standardization, in rapid assessment of freshness, defects difficult to identify by other laboratory methods [14]. Objective is based on the determination made by a group experts, while being used to qualitatively evaluate the taste, aroma, color, consistency and appearance [15].

Sensory analysis is a method that is under the influence of various factors that induce uncertainty, such as: a food temperature, a concentration of specific substances, a physical condition, a degree of dissolution, o the amount of saliva and its quality, a movement of the tongue, a degree of shredding of the product, an age of the taster. In sensory analysis, the perception of experts may be affected by uncertainty and for this reason the qualitative assessment, based on linguistic terms [16]. They consider that the qualitative method of assessing sensory perception in this context is more realistic than the quantitative approach. The values of sensory perception are qualitative evaluations represented by linguistic terms with which experts assess the taste, aroma, color, consistency and appearance of honey [17]. The results recorded for these characteristics can be: unsatisfactory, satisfying, medium, goo, excellent.

These linguistic terms used for the qualitative assessment of sensory attributes (color, aroma, taste, smell and general appearance) are transformed into triplets of numerical values using the membership functions. Thus, the quality of a sensory attribute is assessed using fuzzy logic (working with values between 0 and 1 [18] through three numerical values (on a scale from 0 to 100), which reflects the share of belonging to three of the five values language [19]. The classification of the analyzed samples is based on the comparison of these evaluations based on linguistic terms [20], [21]. In order to meet consumer requirements, the sensory and nutritional properties are analyzed according gualitative quantities represented by linguistic terms [22], [23]. This analysis is based on fuzzy logic that allows processing the data represented by linguistic terms [13]-[15]. To build the fuzzy mathematical model of sensory analysis of bee honey, the number and linguistic terms of the sensory perception analysis scale must be established. Each of the linguistic terms used to assess sensory qualities has a certain meaning, which is represented by a set of values in 
the range $[0,1]$, described by means of a membership, generally to a set of three linguistic terms from the total set of linguistic sizes. For the fuzzy sensory analysis of the honey samples we used membership functions with triangular distribution. Thus, the linguistic terms of perception with which experts appreciate the sensory characteristics of honey varieties are converted into so-called triplets belonging to three of the values of the scale. The triangular belonging functions were used in this model to assess the degree of belonging to three of the linguistic terms, with different weights. For the development of the fuzzy model, we used Matlab R2020b.

\section{Results and Discussions}

American mint honey is a special assortment, because it harmoniously combines a strong essence, flavored with the specific sweetness of this bee product. This exceptional combination of menthol and honey, makes this assortment highly appreciated and recommends it to be used, especially, for sweetening and enriching the teas. This honey has a slightly greenish tint and crystallizes quite quickly, in fine grains. It has a rich content of vitamin $\mathrm{C}$ and is found especially in the areas where the asthma crops are more abundant, in the hill areas, but also in the Danube Delta region. The therapeutic properties of this assortment of honey are:

- it is a toning honey

- has analgesic and soothing properties

- stimulates digestion

- helps in case of biliary dyskinesia

- combat bloating

- relieves abdominal colic

Honey has the following specific sensory characteristics:

- foam-free appearance, without visible foreign bodies,

- the color is from slightly colorless to light yellow, golden yellow, yellow - orange, yellow-dark, ruby, brown yellow, brown - dark,

- specific honey aroma less or more pronounced,

- sweet taste specific to honey,

- homogeneous, fluid, viscous, crystallized consistency.

Table 1: Sensory analysis of mint honey

\begin{tabular}{|c|c|c|c|c|}
\hline $\begin{array}{l}\text { Honey } \\
\text { Parameter }\end{array}$ & Acacia & $\begin{array}{c}\text { Summer } \\
\text { flower }\end{array}$ & Sunflower & Mint \\
\hline Color & $\begin{array}{c}\text { Light } \\
\text { yellow }\end{array}$ & Golden & Reddish & Yellowish green \\
\hline Smell & $\begin{array}{c}\text { With a pleasant aroma well } \\
\text { highlighted }\end{array}$ & $\begin{array}{c}\text { Sunflower } \\
\text { flavored }\end{array}$ & $\begin{array}{c}\text { With menthol } \\
\text { aroma }\end{array}$ \\
\hline Consistency & $\begin{array}{c}\text { Fluid } \\
\text { consistency }\end{array}$ & $\begin{array}{c}\text { Fluid } \\
\text { consistency }\end{array}$ & $\begin{array}{c}\text { Fluid } \\
\text { consistency }\end{array}$ & Fluid consistency \\
\hline Taste & $\begin{array}{c}\text { Sweet taste, } \\
\text { pronounced }\end{array}$ & Sweet taste & Sweet taste & Flavor, sweet taste \\
\hline
\end{tabular}

Sensory analysis, as the scientific method of appreciation of food owner, plays an important role in stabilizing authentic products, being used independently for comparison with reference, classification and standardization, as well as detecting prospects, defects and other shortcomings. more difficult to detect by the other results. Although the sensory analysis is still dependent on the human appreciation, having a certain degree of subjectivism, due to the professionalization of the body of tasters and the interpretation of statistics, it is a useful tool, and in some points it becomes 
irreplaceable in the assessment of quality. Honey must not contain organic or inorganic bodies foreign to its composition, such as: mold, insects, insect fragments, seedlings or impurities, when the honey is marketed as such or used in another product for human consumption. Each attributes in the sensory analysis has a relative weight in the total quality index. This relative weight is established on the basis of the assessments of a set of 20 consumers who provide assessments on the sensory quality of bee honey, as well as on the basis of chemical determinations performed to highlight the quality of honey according to European and national standards. The relative weight that each quality sensory attribute has in the calculation of the global sensory quality index is established using qualitative assessments, based on linguistic terms, using a fuzzy sensory scale with the following five linguistic calories.

$$
\begin{aligned}
& \text { QCrel }=\mathrm{QC} / \mathrm{Qt} ; \\
& \mathrm{QArel}=\mathrm{QA} / \mathrm{Qt} ; \\
& \mathrm{QGrel}=\mathrm{QG} / \mathrm{Qt} ; \\
& \mathrm{QTrel}=\mathrm{QT} / \mathrm{Qt} ; \\
& \mathrm{QOrel}=\mathrm{QO} / \mathrm{Qt} ;
\end{aligned}
$$

Qt is calculated as the sum of the first values in the triplets QC, QA, QG, QT and QO with which the sensory quality is evaluated through the functions of belonging to the linguistic values by consumers. The quality of each attribute of the sensory analysis CC, CA, CG, CT and CO is calculated based on the assessments of 20 consumers who participated in this sensory analysis and who made qualitative assessments using linguistic terms (unsatisfactory, satisfactory, average, good, excellent). These linguistic values are transformed into triplets of numerical values with the help of the functions belonging to three of the linguistic terms. This set of three numerical values that is used to reflect quality for each sensory attribute, in the comparative assessment of bee samples, were used to obtain a global sensory quality index (CS) that sums the products between the calculated sensory

\begin{tabular}{|c|c|c|}
\hline $\begin{array}{l}\text { Sensory } \\
\text { quality } \\
\text { attributes }\end{array}$ & $\begin{array}{l}\text { Calculation of the set of numerical values } \\
\text { associated with quality attributes, in Matlab }\end{array}$ & $\begin{array}{c}\text { Triplets } \\
\text { associated with } \\
\text { quality } \\
\text { attributes }\end{array}$ \\
\hline Color & $\begin{array}{l}\mathrm{QC}=\left(\begin{array}{lll}0 *\left[\begin{array}{lll}0 & 0 & 25\end{array}\right]+0 *\left[\begin{array}{lll}25 & 25 & 25\end{array}\right]+6 *\left[\begin{array}{lll}50 & 25 & 25\end{array}\right] \\
+8 *\left[\begin{array}{llll}75 & 25 & 25\end{array}\right]+6 *\left[\begin{array}{lll}100 & 25 & 0\end{array}\right) / 20\end{array}\right.\end{array}$ & $\begin{array}{lll}75 & 25 & 17.5\end{array}$ \\
\hline Flavor & $\begin{array}{l}\mathrm{QA}=\left(\begin{array}{lll}0 *\left[\begin{array}{lll}0 & 0 & 25\end{array}\right]+0 *\left[\begin{array}{lll}25 & 25 & 25\end{array}\right]+3 *\left[\begin{array}{lll}50 & 25 & 25\end{array}\right] \\
+11 *\left[\begin{array}{lll}75 & 25 & 25\end{array}\right]+6 *\left[\begin{array}{lll}10 & 25 & 0\end{array}\right) / 20\end{array}\right.\end{array}$ & $\begin{array}{lll}78.75 & 25 & 17.5\end{array}$ \\
\hline Taste & $\begin{array}{l}\mathrm{QG}=\left(\begin{array}{lll}0 *\left[\begin{array}{lll}0 & 0 & 25\end{array}\right]+0 *\left[\begin{array}{lll}25 & 25 & 25\end{array}\right]+4 *\left[\begin{array}{lll}50 & 25 & 25\end{array}\right] \\
+10 *\left[\begin{array}{lll}75 & 25 & 25\end{array}\right]+6 *\left[\begin{array}{lll}10 & 25 & 0\end{array}\right) / 20\end{array}\right.\end{array}$ & $\begin{array}{lll}77.5 & 25 & 17.5\end{array}$ \\
\hline Texture & $\begin{array}{l}\mathrm{QT}=\left(\begin{array}{lll}0 *\left[\begin{array}{lll}0 & 0 & 25\end{array}\right]+0 *\left[\begin{array}{lll}25 & 25 & 25\end{array}\right]+6 *\left[\begin{array}{lll}50 & 25 & 25\end{array}\right] \\
+8 *\left[\begin{array}{llll}75 & 25 & 25\end{array}\right]+6 *\left[\begin{array}{lll}100 & 25 & 0\end{array}\right) / 20\end{array}\right.\end{array}$ & $\begin{array}{lll}75 & 25 & 17.5\end{array}$ \\
\hline Appearence & 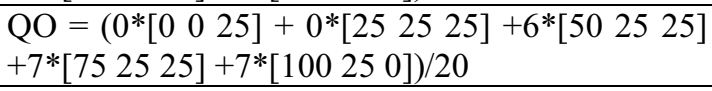 & $\begin{array}{c}76.2525 \\
16.25\end{array}$ \\
\hline & $\mathrm{Qt}=\mathrm{QC}(1)+\mathrm{QA}(1)+\mathrm{QG}(1)+\mathrm{QT}(1)+\mathrm{QO}(1)$ & 382.5 \\
\hline
\end{tabular}
triplets. for each of the quality attributes with the relative weight of each attribute:

$$
\mathrm{CS}=\mathrm{CC} \times \mathrm{QCrel}+\mathrm{CA} \times \mathrm{QArel}+\mathrm{CG} \times \mathrm{QGrel}+\mathrm{CT} \times \mathrm{QTrel}+\mathrm{CO} \times \mathrm{QOrel}
$$

Table 2: Calculation of triplets of sensory quality attributes in the calculation of the global sensory quality index of honey varieties

Table 3: Calculation of the relative weight of sensory quality attributes in the calculation of the global sensory quality index of honey varieties

\begin{tabular}{|l|c|rrr|}
\hline $\begin{array}{c}\text { Sensory } \\
\text { quality } \\
\text { attributes }\end{array}$ & $\begin{array}{c}\text { Calculation of the set of numerical } \\
\text { values associated with quality } \\
\text { attributes, in Matlab }\end{array}$ & \multicolumn{3}{|c|}{$\begin{array}{c}\text { Triplets associated with } \\
\text { quality attributes }\end{array}$} \\
\hline Color & QCrel = QC / Qt & 0.1961 & 0.0654 & 0.0458 \\
\hline Flavor & QArel = QA / Qt & 0.2059 & 0.0654 & 0.0458 \\
\hline Taste & QGrel = QG / Qt & 0.2026 & 0.0654 & 0.0458 \\
\hline Texture & QTrel = QT / Qt & 0.1961 & 0.0654 & 0.0458 \\
\hline
\end{tabular}




\begin{tabular}{|c|c|c|}
\hline Appearence & QOrel $=\mathrm{QO} / \mathrm{Qt}$ & $\begin{array}{lll}0.1993 & 0.0654 & 0.0425\end{array}$ \\
\hline
\end{tabular}

\section{Conclusions}

The American mint honey revealed that seven attributes were significantly including: color, floral aroma, viscosity, consistency, acceptability. American mint honey is very rich in volatile oils, which come from the asthma plant, where the bees collected pollen. For this reason it is a tonic honey for the nervous system, but at the same time it helps and stimulates digestion.

\section{References}

1. A. A. Sawant, N. J. Thakor, S. B. Swami, A. D. Divate, and B. S. K. K. Vidyapeeth, "Physical and sensory characteristics of Ready-To-Eat food prepared from finger millet based composite mixer by extrusion," Agric. Eng. Int. CIGR J., 2013.

2. S. Balasubramanian, D. N. Yadav, J. Kaur, and T. Anand, "Development and shelf-Life evaluation of pearl millet based upma dry mix," J. Food Sci. Technol., 2014, doi: 10.1007/s13197-012-0616-0.

3. S. Shobana et al., "Development and evaluation of nutritional, sensory and glycemic properties of finger millet (Eleusine coracana L.) based food products," Asia Pac. J. Clin. Nutr., 2018, doi: 10.6133/apjen.032017.18.

4. S. E. Kemp, T. Hollowood, and J. Hort, Sensory evaluation: A practical handbook. 2013.

5. S. B. Solanke, R. V. Jaybhaye, and S. B. Jadhav, "Sensory Evaluation of Pearl Millet based Snack Food (Kharodi) using Fuzzy Logic," Int. J. Curr. Microbiol. Appl. Sci., 2018, doi: 10.20546/ijcmas.2018.704.244.

6. S. Vanishree, M. R. Kammar, and U. Nidoni, "Development and Evaluation of Pearl Millet Based Novel Health Drink," Indian J. Nutr. Diet., 2016, doi: 10.21048/ijnd.2016.53.4.8404.

7. S. Gaur, "Iron Bioavailability, Storability and Sensory Evaluation of Iron Fortified Extruded Snacks Intended to Alleviate Iron Deficiency in Indian Children," Int. J. Nutr. Food Sci., 2015, doi: 10.11648/j.ijnfs.20150401.16.

8. T. M. Aande, I. G. Agbidye, and C. A. Adah, "Formulation, Proximate Analysis and Sensory Evaluation of \&lt;i\&gt;Mumu\&lt;/i\&gt; from Pearl Millet, Irish Potato and Sesame Seed Blend," Agric. Sci., 2020, doi: 10.4236/as.2020.113015.

9. Priya S S and Kowsalya S, "Formulation and evaluation and convenience food mixes from malted millets," Int. J. Sci. Res., 2015, doi: www.theglobaljournals.com/ijsr/articles.php?

10. A. Mehra and U. Singh, "Development, Organoleptic And Nutritional Evaluation Of Pearl Millet Based Mathri," Int. J. Eng. Technol. Sci. Res., 2017.

11. E. P. Köster, "Diversity in the determinants of food choice: A psychological perspective," Food Qual. Prefer., 2009, doi: 10.1016/j.foodqual.2007.11.002.

12. B. Dhillon, N. S. Sodhi, S. Gandotra, S. Kaur, and S. Jaiswal, "Physico-chemical and textural (sensorial and electromyographic) evaluation of idlis formulated with brown rice and pearl millet flours," J. Food Meas. Charact., 2020, doi: 10.1007/s11694-020-00534-w.

13. N. Kaushik, A. R. Gondi, R. Rana, and P. Srinivasa Rao, “Application of fuzzy logic technique for sensory evaluation of high pressure processed mango pulp and litchi juice and its comparison to thermal treatment," Innov. Food Sci. 
Emerg. Technol., 2015, doi: 10.1016/j.ifset.2015.08.007.

14. K. J. Shinde and I. L. Pardeshi, "Fuzzy Logic Model for Sensory Evaluation of Commercially Available Jam," J. Ready to eat food, 2014.

15. C. Ayca and K. Hasan, "An application of fuzzy analytic hierarchy process (FAHP) for evaluating students project," Educ. Res. Rev., 2017, doi: 10.5897/err2016.3065.

16. Y. Chen, X. Zeng, M. Happiette, P. Bruniaux, R. Ng, and W. Yu, "Optimisation of garment design using fuzzy logic and sensory evaluation techniques," Eng. Appl. Artif. Intell., 2009, doi: 10.1016/j.engappai.2008.05.007.

17. N. Perrot, I. Ioannou, I. Allais, C. Curt, J. Hossenlopp, and G. Trystram, "Fuzzy concepts applied to food product quality control: A review," Fuzzy Sets Syst., 2006, doi: 10.1016/j.fss.2005.12.013.

18. X. Wang, D. Li, and X. Shi, "A fuzzy model for aggregative food safety risk assessment in food supply chains," Prod. Plan. Control, 2012, doi: 10.1080/09537287.2011.561812.

19. C. J. Du and D. W. Sun, "Recent developments in the applications of image processing techniques for food quality evaluation," Trends Food Sci. Technol., 2004, doi: 10.1016/j.tifs.2003.10.006.

20. Y. P. Tsang, K. L. Choy, C. H. Wu, G. T. S. Ho, and H. Y. Lam, "BlockchainDriven IoT for Food Traceability with an Integrated Consensus Mechanism," IEEE Access, 2019, doi: 10.1109/ACCESS.2019.2940227.

21. S. Khan, M. I. Khan, A. Haleem, and A. R. Jami, "Prioritising the risks in Halal food supply chain: an MCDM approach," J. Islam. Mark., 2019, doi: 10.1108/JIMA-10-2018-0206.

22. G. Egilmez, S. Gumus, M. Kucukvar, and O. Tatari, “A fuzzy data envelopment analysis framework for dealing with uncertainty impacts of input-output life cycle assessment models on eco-efficiency assessment," J. Clean. Prod., 2016, doi: 10.1016/j.jclepro.2016.03.111.

23. P. Morone, P. M. Falcone, and A. Lopolito, "How to promote a new and sustainable food consumption model: A fuzzy cognitive map study," J. Clean. Prod., 2019, doi: 10.1016/j.jclepro.2018.10.075. 